\title{
ELZAKI TRANSFORM HOMOTOPY PERTURBATION METHOD FOR SOLVING GAS DYNAMICS EQUATION
}

\author{
Prem Kiran G. Bhadane ${ }^{1}$, V. H. Pradhan ${ }^{2}$ \\ ${ }^{1}$ Assistant Professor, Department of Applied Sciences, RCPIT, Maharashtra, India, \\ ${ }^{2}$ Associate Professor, Department of Applied Mathematics and Humanities, SVNIT, Gujarat, India \\ omprem07@gmail.com,pradhan65@yahoo.com
}

\begin{abstract}
In this paper, the ELzaki transform homotopy perturbation method (ETHPM) has been successfully applied to obtain the approximate analytical solution of the nonlinear homogeneous and non-homogeneous gas dynamics equations. The proposed method is an elegant combination of the new integral transform "ELzaki Transform" and the homotopy perturbation method. The method is really capable of reducing the size of the computational work besides being effective and convenient for solving nonlinear equations. The proposed iterative scheme finds the solution without any discretization, linearization or restrictive assumptions. A clear advantage of this technique over the decomposition method is that no calculation of Adomian's polynomials is needed.
\end{abstract}

Keywords: ELzaki transform, Homotopy perturbation method, non linear partial differential equation, and nonlinear gas dynamics equation

\section{INTRODUCTION}

In recent years, many research workers have paid attention to find the solution of nonlinear differential equations by using various methods. Among these are the Adomian decomposition method [Hashim, Noorani, Ahmed. Bakar, Ismail and Zakaria, (2006)], the tanh method, the homotopy perturbation method [ Sweilam, Khader (2009), Sharma and Giriraj Methi (2011), Jafari, Aminataei (2010), (2011) ], the differential transform method [(2008)], homotopy perturbation transform method and the variational iteration method. Various ways have been proposed recently to deal with these nonlinearities; one of these combinations is ELzaki transform and homotopy perturbation method. ELzaki transform is a useful technique for solving linear differential equations but this transform is totally incapable of handling nonlinear equations $[6,7]$ because of the difficulties that are caused by the nonlinear terms. This paper is using homotopy perturbation method to decompose the nonlinear term, so that the solution can be obtained by iteration procedure. This means that we can use both ELzaki transform and homotopy perturbation methods to solve many nonlinear problems. The main aim of this paper is to consider the effectiveness of the Elzaki transform homotopy perturbation method in solving nonlinear gas dynamics equation. This method provides the solution in a rapid convergent series which may leads the solution in a closed form. The fact that the proposed technique solves nonlinear problems without using so-called Adomian's polynomials is a clear advantage of this algorithm over the decomposition method.
Gas dynamics is a science in the branch of fluid dynamics concerned with studying the motion of gases and its effects on physical systems, based on the principles of fluid mechanics and thermodynamics. The science arises from the studies of gas flows, often around or within physical bodies, some examples of these studies include but not limited to choked flows in nozzles and valves, shock waves around jets, aerodynamic heating on atmospheric reentry vehicles and flows of gas fuel within a jet engine.

The equations of gas dynamics [4] are mathematical expressions based on the physical laws of conservation, namely, the laws of conservation of mass, conservation of momentum, conservation of energy, and so forth. The nonlinear equations of ideal gas dynamics are applicable for three types of nonlinear waves like shock fronts, rare factions, and contact discontinuities. Different types of gas dynamics equations in physics have been solved by Evans and Bulut [2002], Polyanin and Zaitsev [2004], Elizarova, Jafari et al.[2009], Hossein Aminikhah, Ali Jamalian [2013] and Ames, by applying various kinds of analytical and numerical methods.

In this paper, we obtained the solution of gas dynamics equation by using a new method called as ELzaki transform homotopy perturbation method. We obtain an analytical approximation to the solution of the nonlinear gas dynamic equation using ETHPM. The gas dynamics equation as a nonlinear model is as follows [4] 


$$
\frac{\partial u}{\partial t}+u \frac{\partial u}{\partial x}-u(1-u)=0,0 \leq x \leq 1, t>0,
$$

The present paper discusses the analytical approximate solution of the nonlinear gas dynamic equation.

\section{ELZAKI TRANSFORM HOMOTOPY PERTURBATION METHOD [6]}

Consider a general nonlinear non-homogenous partial differential equation with initial conditions of the form:

$$
\begin{aligned}
& \mathrm{Du}(\mathrm{x}, \mathrm{t})+\mathrm{Ru}(\mathrm{x}, \mathrm{t})+\mathrm{Nu}(\mathrm{x}, \mathrm{t})=\mathrm{g}(\mathrm{x}, \mathrm{t}) \\
& \mathrm{u}(\mathrm{x}, 0)=\mathrm{h}(\mathrm{x}) \quad, \quad \mathrm{u}_{\mathrm{t}}(\mathrm{x}, 0)=\mathrm{f}(\mathrm{x})
\end{aligned}
$$

where $\mathrm{D}$ is linear differential operator of order two, $\mathrm{R}$ is linear differential operator of less order than $\mathrm{D}, \mathrm{N}$ is the general nonlinear differential operator and $g(x, t)$ is the source term.

Taking ELzaki transform on both sides of equation (2), to get:

$$
E[\operatorname{Du}(x, t)]+E[R u(x, t)]+E[N u(x, t)]=E[g(x, t)]
$$

Using the differentiation property of ELzaki transform and above initial conditions, we have:

$$
\begin{gathered}
E[u(x, t)]=v^{2} E[g(x, t)]+v^{2} h(x)+v^{3} f(x) \\
-v^{2} E[\operatorname{Ru}(x, t)+N u(x, t)]
\end{gathered}
$$

Applying the inverse ELzaki transform on both sides of equation (4), to find:

$$
\mathrm{u}(\mathrm{x}, \mathrm{t})=\mathrm{G}(\mathrm{x}, \mathrm{t})-\mathrm{E}^{-1}\left\{\mathrm{v}^{2} \mathrm{E}[\mathrm{Ru}(\mathrm{x}, \mathrm{t})+\mathrm{Nu}(\mathrm{x}, \mathrm{t})]\right\}
$$

where $G(x, t)$ represents the term arising from the source term and the prescribed initial condition.

Now, we apply the homotopy perturbation method,

$$
u(x, t)=\sum_{n=0}^{\infty} p^{n} u_{n}(x, t)
$$

and the nonlinear term can be decomposed as

$$
\mathrm{N}[\mathrm{u}(\mathrm{x}, \mathrm{t})]=\sum_{\mathrm{n}=0}^{\infty} \mathrm{p}^{\mathrm{n}} \mathrm{H}_{\mathrm{n}}(\mathrm{u})
$$

where $H_{n}(u)$ are He's polynomial and given by

$$
\begin{gathered}
H_{n}\left(u_{0}, u_{1}, \ldots \ldots . u_{n}\right)=\frac{1}{n !} \frac{\partial^{n}}{\partial p^{n}}\left[N\left(\sum_{i=0}^{\infty} p^{i} u_{i}\right)\right]_{p=0}, \\
n=0,1,2, \ldots \ldots \ldots
\end{gathered}
$$

Substituting equations (6) and (7) in equation (5), we get:

$$
\begin{aligned}
& \sum_{n=0}^{\infty} p^{n} u_{n}(x, t)=G(x, t)- \\
& p\left\{E^{-1}\left[v^{2} E\left[R \sum_{n=0}^{\infty} p^{n} u_{n}(x, t)+\sum_{n=0}^{\infty} p^{n} H_{n}(u)\right]\right]\right\}
\end{aligned}
$$

This is the coupling of the ELzaki transform and the homotopy perturbation method. Comparing the coefficient of like powers of $\mathrm{p}$, the following approximations are obtained.

$$
\begin{gathered}
\mathrm{p}^{0}: \mathrm{u}_{0}(\mathrm{x}, \mathrm{t})=\mathrm{G}(\mathrm{x}, \mathrm{t}) \\
\mathrm{p}^{1}: \mathrm{u}_{1}(\mathrm{x}, \mathrm{t})=-\mathrm{E}^{-1}\left\{\mathrm{v}^{2} \mathrm{E}\left[\mathrm{Ru}_{0}(\mathrm{x}, \mathrm{t})+\mathrm{H}_{0}(\mathrm{u})\right]\right\} \\
\mathrm{p}^{2}: \mathrm{u}_{2}(\mathrm{x}, \mathrm{t})=-\mathrm{E}^{-1}\left\{\mathrm{v}^{2} \mathrm{E}\left[\mathrm{Ru}_{1}(\mathrm{x}, \mathrm{t})+\mathrm{H}_{1}(\mathrm{u})\right]\right\} \\
\mathrm{p}^{3}: \mathrm{u}_{3}(\mathrm{x}, \mathrm{t})=-\mathrm{E}^{-1}\left\{\mathrm{v}^{2} \mathrm{E}\left[\mathrm{Ru}_{2}(\mathrm{x}, \mathrm{t})+\mathrm{H}_{2}(\mathrm{u})\right]\right\}
\end{gathered}
$$

Then the solution is

$$
\begin{aligned}
u(x, t) & =\lim _{p \rightarrow 1} u_{n}(x, t) \\
& =u_{0}(x, t)+u_{1}(x, t)+u_{2}(x, t)+\ldots
\end{aligned}
$$

\section{APPLICATIONS}

In this section, the effectiveness and the usefulness of ELzaki transform homotopy perturbation method (ETHPM) are demonstrated by finding exact solutions of homogeneous and nonhomogeneous nonlinear gas dynamics equations.

Example 3.1 Consider the nonlinear gas dynamic equation

$$
\frac{\partial u}{\partial t}+u \frac{\partial u}{\partial x}-u(1-u)=0
$$

with the following initial condition

$$
u(x, 0)=e^{-x}
$$

By applying ELzaki transform on both side of equation (11)

$$
E\left[\frac{\partial u}{\partial t}\right]=E\left[u-u^{2}-u \frac{\partial u}{\partial x}\right]
$$

Using differential properties of ELzaki transform, Eq. (13) can be written as

$$
\frac{1}{v} E[u(x, t)]-v u(x, 0)=E\left[u-u^{2}-u \frac{\partial u}{\partial x}\right]
$$


Using initial condition (12), Eq. (14) can be written as

$$
E[u(x, t)]=v^{2} e^{-x}+v E\left[u-u^{2}-u \frac{\partial u}{\partial x}\right]
$$

Taking inverse ELzaki transform on both sides of Eq. (15), we get

$$
u(x, t)=e^{-x}+E^{-1}\left\{v E\left[u-u^{2}-u \frac{\partial u}{\partial x}\right]\right\}
$$

Now we apply the homotopy perturbation method,

$$
u(x, t)=\sum_{n=0}^{\infty} p^{n} u_{n}(x, t)
$$

and the nonlinear term can be decomposed as

$$
\mathrm{N}[\mathrm{u}(\mathrm{x}, \mathrm{t})]=\sum_{\mathrm{n}=0}^{\infty} \mathrm{p}^{\mathrm{n}} \mathrm{H}_{\mathrm{n}}(\mathrm{u})
$$

Using Eqs. (17)- (18) into Eq. (16), we get

$$
\begin{aligned}
& \sum_{n=0}^{\infty} p^{n} u_{n}(x, t)= \\
& e^{-x}+p E^{-1}\left\{v E\left[\sum_{n=0}^{\infty} p^{n} u_{n}(x, t)-\sum_{n=0}^{\infty} p^{n} H_{n}(u)\right]\right\}
\end{aligned}
$$

where $H_{n}(u)$ are He's polynomials. The first three components of He's polynomials are given by

$$
\begin{gathered}
\mathrm{H}_{0}(u)=\mathrm{u}_{0}^{2}+\mathrm{u}_{0} \frac{\partial \mathrm{u}_{0}}{\partial \mathrm{x}} \\
\mathrm{H}_{1}(\mathrm{u})=2 \mathrm{u}_{0} \mathrm{u}_{1}+\mathrm{u}_{0} \frac{\partial \mathrm{u}_{1}}{\partial \mathrm{x}}+\mathrm{u}_{1} \frac{\partial \mathrm{u}_{0}}{\partial \mathrm{x}} \\
\mathrm{H}_{2}(\mathrm{u})=2 \mathrm{u}_{0} \mathrm{u}_{2}+\mathrm{u}_{0} \frac{\partial \mathrm{u}_{2}}{\partial \mathrm{x}}+\mathrm{u}_{1} \frac{\partial \mathrm{u}_{1}}{\partial \mathrm{x}}+\mathrm{u}_{2} \frac{\partial \mathrm{u}_{0}}{\partial \mathrm{x}}+\mathrm{u}_{1}^{2}
\end{gathered}
$$

Comparing the coefficient of various power of $p$ in (19), we get

$$
\begin{gathered}
\mathrm{p}^{0}: \mathrm{u}_{0}(\mathrm{x}, \mathrm{t})=\mathrm{e}^{-\mathrm{x}}, \\
\mathrm{p}^{1}: \mathrm{u}_{1}(\mathrm{x}, \mathrm{t})=\mathrm{E}^{-1}\left\{\mathrm{vE}\left[\mathrm{u}_{0}-\mathrm{H}_{0}(\mathrm{u})\right]\right\} \\
=\mathrm{E}^{-1}\left\{\mathrm{vE}\left[\mathrm{u}_{0}-\mathrm{u}_{0}^{2}-\mathrm{u}_{0} \frac{\partial \mathrm{u}_{0}}{\partial \mathrm{x}}\right]\right\}=\mathrm{e}^{-\mathrm{x}_{\mathrm{t}}}, \\
\mathrm{p}^{2}: \mathrm{u}_{2}(\mathrm{x}, \mathrm{t})=\mathrm{E}^{-1}\left\{\mathrm{vE}\left[\mathrm{u}_{1}-\mathrm{H}_{1}(\mathrm{u})\right]\right\}
\end{gathered}
$$

$$
\begin{aligned}
= & \mathrm{E}^{-1}\left\{\mathrm{vE}\left[\mathrm{u}_{1}-2 \mathrm{u}_{0} \mathrm{u}_{1}-\mathrm{u}_{0} \frac{\partial \mathrm{u}_{1}}{\partial \mathrm{x}}-\mathrm{u}_{1} \frac{\partial \mathrm{u}_{0}}{\partial \mathrm{x}}\right]\right\} \\
= & \mathrm{E}^{-1}\left\{\mathrm{vE}\left[\mathrm{e}^{-\mathrm{x}} \mathrm{t}\right]\right\}=\mathrm{e}^{-\mathrm{x}} \frac{\mathrm{t}^{2}}{2 !},
\end{aligned}
$$$$
\mathrm{p}^{3}: \mathrm{u}_{3}(\mathrm{x}, \mathrm{t})=\mathrm{E}^{-1}\left\{\mathrm{vE}\left[\mathrm{u}_{2}-\mathrm{H}_{2}(\mathrm{u})\right]\right\}
$$

$$
\begin{aligned}
= & E^{-1}\left\{v E \left[u_{2}-2 u_{0} u_{2}-u_{0} \frac{\partial u_{2}}{\partial x}-u_{1} \frac{\partial u_{1}}{\partial x}\right.\right. \\
& \left.\left.-u_{2} \frac{\partial u_{0}}{\partial x}-u_{1}^{2}\right]\right\}=e^{-x} \frac{t^{3}}{3 !},
\end{aligned}
$$

Proceeding in similar manner we can obtain further values,

$$
\begin{aligned}
& p^{4}: u_{4}(x, t)=e^{-x} \frac{t^{4}}{4 !}, \\
& p^{5}: u_{5}(x, t)=e^{-x} \frac{t^{5}}{5 !}
\end{aligned}
$$

substituting above values in equation (10), we get solution in the form of a series

$$
\begin{aligned}
& u(x, t)=u_{0}(x, t)+u_{1}(x, t)+u_{2}(x, t)+\ldots \\
& =e^{-x}+e^{-x} t+e^{-x} \frac{t^{2}}{2 !}+e^{-x} \frac{t^{3}}{3 !}+e^{-x} \frac{t^{4}}{4 !}+e^{-x} \frac{t^{5}}{5 !}+\cdots \\
& =e^{-x}\left(1+t+\frac{t^{2}}{2 !}+\frac{t^{3}}{3 !}+\frac{t^{4}}{4 !}+\frac{t^{5}}{5 !}+\cdots \cdots \cdots\right)=e^{t-x},(20)
\end{aligned}
$$

This is the solution of (11) and which is exactly the exact solution of the problem $[2,3,4,5]$. Figure 1 shows the graph of $\mathrm{u}=\mathrm{e}^{\mathrm{t}-\mathrm{x}}, \mathrm{t}>0$ and $0 \leq x \leq 1$.

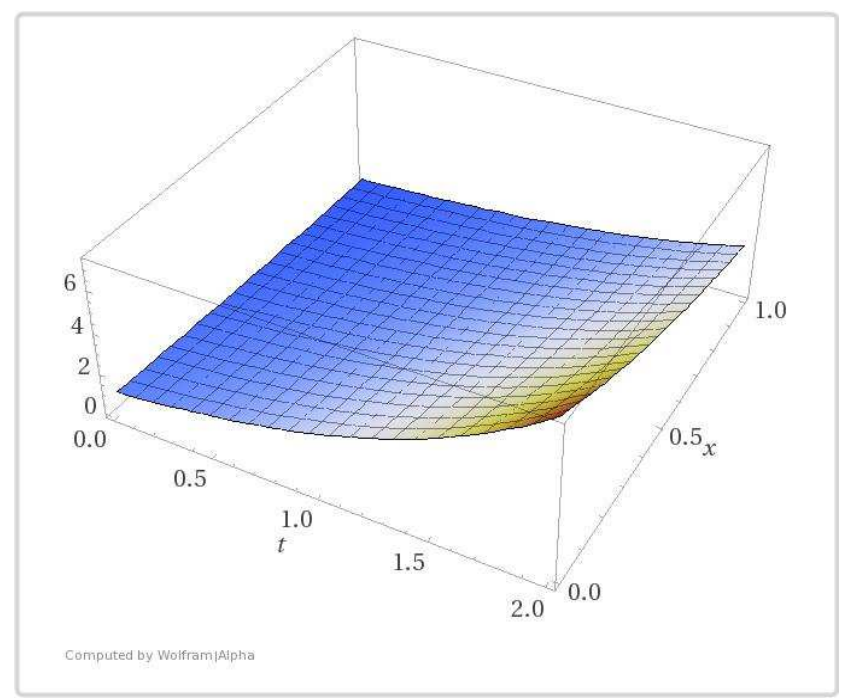

Fig -1: Graph of $\mathrm{u}=\mathrm{e}^{\mathrm{t}-\mathrm{x}}, \mathrm{t}>0$ and $0 \leq x \leq 1$. 
Example 3.2 Consider the following nonhomogeneous nonlinear gas dynamic equation

$$
\frac{\partial u}{\partial t}+u \frac{\partial u}{\partial x}-u(1-u)=-e^{t-x}
$$

with the following initial condition

$$
\mathrm{u}(\mathrm{x}, 0)=1-\mathrm{e}^{-\mathrm{x}}
$$

By applying ELzaki transform on both side of equation (21)

$$
E\left[\frac{\partial u}{\partial t}\right]=E\left[u-u^{2}-u \frac{\partial u}{\partial x}\right]-E\left[e^{t-x}\right]
$$

Using properties of ELzaki transform, we have

$\frac{1}{v} E[u(x, t)]-v u(x, 0)=E\left[u-u^{2}-u \frac{\partial u}{\partial x}\right]-e^{-x} \frac{v^{2}}{1-v}$

Using initial condition (22), Eq. (24) can be written as

$\mathrm{E}[\mathrm{u}(\mathrm{x}, \mathrm{t})]=$

$v^{2}\left(1-e^{-x}\right)+v E\left[u-u^{2}-u \frac{\partial u}{\partial x}\right]-v e^{-x} \frac{v^{2}}{1-v}$

Taking inverse ELzaki transform on both sides of Eq. (25), we get

$u(x, t)=\left(1-e^{-x}\right)+E^{-1}\left\{v E\left[u-u^{2}-u \frac{\partial u}{\partial x}\right]-e^{-x} \frac{v^{3}}{1-v}\right\}$

Since

$\mathrm{E}^{-1}\left\{\mathrm{e}^{-\mathrm{x}} \frac{\mathrm{v}^{3}}{1-\mathrm{v}}\right\}=\mathrm{e}^{-\mathrm{x}} \mathrm{E}^{-1}\left\{\frac{\mathrm{v}^{2}}{1-\mathrm{v}}-\mathrm{v}^{2}\right\}=\mathrm{e}^{-\mathrm{x}}\left(\mathrm{e}^{\mathrm{t}}-1\right)$,

Therefore, we get

$\mathrm{u}(\mathrm{x}, \mathrm{t})=$

$$
\left(1-e^{-x}\right)+E^{-1}\left\{v E\left[u-u^{2}-u \frac{\partial u}{\partial x}\right]\right\}-e^{-x}\left(e^{t}-1\right)
$$

Now we apply the homotopy perturbation method,

$$
u(x, t)=\sum_{n=0}^{\infty} p^{n} u_{n}(x, t)
$$

and the nonlinear term can be decomposed as

$$
\mathrm{N}[\mathrm{u}(\mathrm{x}, \mathrm{t})]=\sum_{\mathrm{n}=0}^{\infty} \mathrm{p}^{\mathrm{n}} \mathrm{H}_{\mathrm{n}}(\mathrm{u})
$$

Using Eqs. (27)- (28) into Eq. (26), we get

$$
\begin{aligned}
& \sum_{n=0}^{\infty} p^{n} u_{n}(x, t)= \\
& \left(1-e^{t-x}\right)+p E^{-1}\left\{v E\left[\sum_{n=0}^{\infty} p^{n} u_{n}(x, t)-\sum_{n=0}^{\infty} p^{n} H_{n}(u)\right]\right\}
\end{aligned}
$$

where $H_{n}(u)$ are He's polynomials. The first three components of He's polynomials are given by

$$
\mathrm{H}_{0}(\mathrm{u})=\mathrm{u}_{0}^{2}+\mathrm{u}_{0} \frac{\partial \mathrm{u}_{0}}{\partial \mathrm{x}}
$$

$$
\mathrm{H}_{1}(\mathrm{u})=2 \mathrm{u}_{0} \mathrm{u}_{1}+\mathrm{u}_{0} \frac{\partial \mathrm{u}_{1}}{\partial \mathrm{x}}+\mathrm{u}_{1} \frac{\partial \mathrm{u}_{0}}{\partial \mathrm{x}}
$$

$$
\mathrm{H}_{2}(\mathrm{u})=2 \mathrm{u}_{0} \mathrm{u}_{2}+\mathrm{u}_{0} \frac{\partial \mathrm{u}_{2}}{\partial \mathrm{x}}+\mathrm{u}_{1} \frac{\partial \mathrm{u}_{1}}{\partial \mathrm{x}}+\mathrm{u}_{2} \frac{\partial \mathrm{u}_{0}}{\partial \mathrm{x}}+\mathrm{u}_{1}^{2} ; \ldots \ldots .
$$

Comparing the coefficient of various power of $p$ in (19), we get

$$
\mathrm{p}^{0}: \mathrm{u}_{0}(\mathrm{x}, \mathrm{t})=1-\mathrm{e}^{\mathrm{t}-\mathrm{x}},
$$

$$
\begin{aligned}
& \mathrm{p}^{1}: \mathrm{u}_{1}(\mathrm{x}, \mathrm{t})=\mathrm{E}^{-1}\left\{\mathrm{vE}\left[\mathrm{u}_{0}-\mathrm{H}_{0}(\mathrm{u})\right]\right\} \\
&=\mathrm{E}^{-1}\left\{\mathrm{vE}\left[\mathrm{u}_{0}-\mathrm{u}_{0}^{2}-\mathrm{u}_{0} \frac{\partial \mathrm{u}_{0}}{\partial \mathrm{x}}\right]\right\} \\
&=\mathrm{E}^{-1}\left\{\mathrm{vE}\left[\left(1-\mathrm{e}^{\mathrm{t}-\mathrm{x}}\right)-\left(1-\mathrm{e}^{\mathrm{t}-\mathrm{x}}\right)^{2}-\left(1-\mathrm{e}^{\mathrm{t}-\mathrm{x}}\right) \mathrm{e}^{\mathrm{t}-\mathrm{x}}\right]\right\} \\
&=\mathrm{E}^{-1}\{\mathrm{vE}[0]\}=0,
\end{aligned}
$$

Proceeding in similar manner we can obtain further values,

$$
\begin{gathered}
p^{2}: u_{2}(x, t)=0, \\
p^{3}: u_{3}(x, t)=0, \ldots \ldots
\end{gathered}
$$

substituting above values in equation (10), we get solution in the form of a series

$$
\begin{gathered}
u(x, t)=u_{0}(x, t)+u_{1}(x, t)+u_{2}(x, t)+\ldots \\
u(x, t)=\left(1-e^{t-x}\right)+0+0+0 \ldots=1-e^{t-x} .
\end{gathered}
$$

This is the solution of (21) and which is exactly the exact solution of the problem $[2,3,4,5]$. Figure 2 shows the graph of $\mathrm{u}=1-\mathrm{e}^{\mathrm{t}-\mathrm{x}}, \mathrm{t}>0$ and $0 \leq x \leq 1$. 


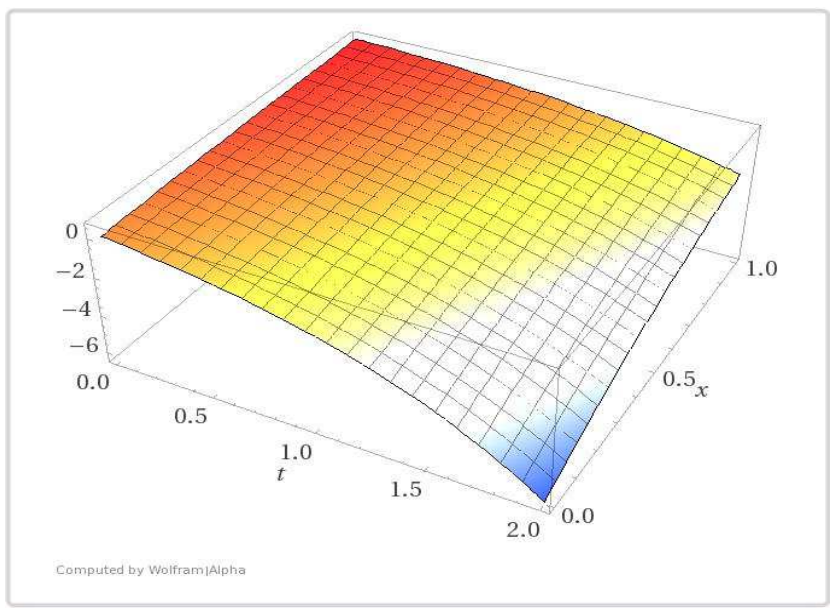

Fig -2: Graph of $\mathrm{u}=1-\mathrm{e}^{\mathrm{t}-\mathrm{x}}, \mathrm{t}>0$ and $0 \leq x \leq 1$.

\section{CONCLUSIONS}

The main goal of this paper is to show the applicability of the mixture of new integral transform "ELzaki transform" with the homotopy perturbation method to construct an analytical solution for gas dynamics equation. This combination of two methods successfully worked to give very reliable and exact solutions to the equation. This method provides an analytical approximation in a rapidly convergent sequence with in exclusive manner computed terms. Its rapid convergence shows that the method is trustworthy and introduces a significant improvement in solving nonlinear partial differential equations over existing methods.

\section{ACKNOWLEDGEMENTS}

I am deeply grateful to the management of Shirpur Education Society, Shirpur (Maharashtra) without whose support my research work would not have been possible. I would also like to extend my gratitude to the Prin. Dr. J. B. Patil and Mr. S. P. Shukla, Head of Department of Applied Sciences, RCPIT for helping and inspiring me for the research work.

\section{REFERENCES}

[1] D.J. Evans, H. Bulut (2002), A new approach to the gas dynamics equation: An application of the decomposition method, Appl. Comp. Math., 79, pp817822.

[2] H. Jafari, M. Zabihi, M. Saidy (2008), Application of homotopy perturbation method for solving gas dynamics equation, Appl. Math. Scie., 2, pp 23932396.

[3] Hossein Jafari, Hassan Hosseinzadehb and Elham Salehpoor (2008), A New Approach to the Gas Dynamics Equation : An Application of the Variational Iteration Method, Applied Mathematical Sciences, Vol.2,No.48,pp2397-2400.
[4] Hossein Aminikhah, Ali Jamalian (2013), Research Article: Numerical Approximation for Nonlinear Gas Dynamic Equation, International Journal of Partial Differential Equations, Vol.2013, Article ID 846749, 7 pages.

[5] M. Matinfar, M.Saeidy, M. Mahdavi and M. Rezael (2011), Variational iteration method for exact solution of gas dynamics equation using He's polynomials, Bulletin of Mathematical Analysis and Applications, Vol.3,No.3,pp 50-55.

[6] Tarig M. Elzaki and Eman M. A. Hilal (2012), Homotopy Perturbation and ELzaki Transform for solving Nonlinear Partial Differential equations, Mathematical Theory and Modeling, Vol.2,No.3, pp3342.

[7] Tarig M. Elzaki and Salih M. Elzaki (2011), Applications of New Transform "ELzaki Transform" to Partial Differential Equations, Global Journal of Pure and Applied Mathematics, Vol.7, No.1,pp65-70.

[8] Tarig M. Elzaki (2011), The New Integral Transform "ELzaki Transform", Global Journal of Pure and Applied Mathematics, Vol.7, No.1,pp57-64. 